\title{
Ginkgo biloba leaf extract prevents diabetic nephropathy through the suppression of tissue transglutaminase
}

\author{
XIAOYAN YU ${ }^{1 *}$, QING SU $^{1 *}$, JIANAN GENG ${ }^{1}$, HUI LIU ${ }^{2}$, YUMENG LIU ${ }^{1}$, \\ JINMING LIU ${ }^{1}$, YAN SHI ${ }^{1}$ and YINGGANG ZOU ${ }^{3}$
}

${ }^{1}$ Department of Experimental Pharmacology and Toxicology, School of Pharmaceutical Sciences, Jilin University, Changchun,
Jilin 130021; ${ }^{2}$ Department of Anatomy, College of Basic Medical Science, Jilin University, Changchun, Jilin 130012;
${ }^{3}$ Department of Obstetrics and Gynecology, The Second Hospital, Jilin University, Changchun, Jilin 130041, P.R. China

Received July 28, 2020; Accepted January 18, 2021

DOI: $10.3892 /$ etm.2021.9764

\begin{abstract}
The present study aimed to investigate the preventive effects of Ginkgo biloba leaf extract (GBE) against extracellular matrix (ECM) accumulation in a streptozotocin (STZ)-induced rat model of diabetic nephropathy (DN), and to determine its underlying molecular mechanism. In vivo, a rat model of DN was established by intraperitoneal injection of STZ, and the rats were subsequently administered GBE. The results demonstrated that GBE significantly decreased blood glucose, the urine protein excretion rate and ECM accumulation in DN rats. In addition, the development of DN significantly induced tissue transglutaminase (tTG) protein expression, which was detected by immunohistochemistry, western blotting and PCR analyses, while GBE administration decreased tTG expression in the diabetic kidney. In vitro, rat glomerular mesangial cells (HBZY-1 cells) cultured with high glucose were also treated with GBE. The concentrations of tTG, fibronectin, type IV collagen, transforming growth factor (TGF)- $\beta$ and connective tissue growth factor (CTGF) were detected via ELISA. The results demonstrated that GBE notably decreased the concentration of these proteins, and tTG expression was positively associated with TGF- $\beta$. GBE also suppressed tTG expression of high glucose-treated HBZY-1 cells in a concentration-dependent manner. Furthermore, tTG protein expression was detected in high glucose-treated HBZY-1 cells transfected with small interfering RNA (siRNA) oligonucleotides against TGF- $\beta$ and CTGF to investigate a possible mechanism of GBE-mediated inhibition of tTG. The
\end{abstract}

Correspondence to: Professor Yinggang Zou, Department of Obstetrics and Gynecology, The Second Hospital, Jilin University, 218 Ziqiang Street, Changchun, Jilin 130041, P.R. China

E-mail: zouyg@jlu.edu.cn

*Contributed equally

Key words: Ginkgo biloba leaf extract, diabetic nephropathy, extracellular matrix, tissue transglutaminase, transforming growth factor- $\beta$, connective tissue growth factor results demonstrated that the tTG levels remained unchanged in CTGF siRNA-transfected cells, but were decreased in the GBE + CTGF siRNA group compared with the control siRNA group, suggesting that tTG may not be regulated by CTGF, and the inhibitory effect of GBE on TTG may not be associated with the direct inhibition of CTGF. However, tTG expression was decreased following the transfection with TGF- $\beta$ siRNA, in which levels of tTG were similar compared with both the GBE group and GBE + TGF- $\beta$ siRNA group, indicating that tTG may be regulated by TGF- $\beta$, and that the GBE-induced repression of tTG expression may be associated with the downregulation of TGF- $\beta$. Taken together, the results of the present study suggest that GBE prevented ECM accumulation by suppressing tTG expression in DN, which was predominantly mediated by TGF- $\beta$.

\section{Introduction}

Diabetes is a chronic progressive disease associated with endocrine and metabolic disorders, and common clinical characteristics include proteinuria, progressive renal damage, hypertension and oedema (1). Diabetes is considered a serious threat to human health, and is the most prevalent disease, apart from cardiovascular disease and cancer (2). There are a number of complications associated with diabetes, such as an increased risk of a cerebrovascular accident, coronary heart disease and retinopathy (3). Diabetic nephropathy (DN) with extracellular matrix (ECM) accumulation is a common characteristic of diabetes (1). Physiologically, ECM synthesis and degradation is balanced; however, under several pathophysiological conditions, the balance is disrupted, which results in ECM accumulation, glomerular structure damage and glomerular sclerosis, ultimately causing DN (4).

Tissue transglutaminase (tTG) is a member of the $\mathrm{Ca}^{2+}$-dependent TG family, which catalyzes the formation of the $\gamma$-glutamyl- $\varepsilon$-lysine isopeptide bond and introduces a covalent crosslink between the protein and peptide, thus inducing resistance to enzymatic degradation (5). tTG is predominantly located in the cytoplasm, while small amounts exist in the nucleus and nuclear membrane under normal physiological conditions (6). Under high levels of glucose, tTG expression increases, the protein translocates to the outside of the cell 
and crosslinks with type IV collagen (Col IV) and fibronectin (FN), which are major constituents of the ECM (7). The crosslinked product is highly stable and difficult to degrade (8). In a previous study, the administration of specific inhibitors of tTG to streptozotocin (STZ)-induced DN rats was found to significantly decrease the abundance of the extracellular crosslinked product (9). Therefore, tTG is considered a regulator of the ECM and is involved in the development of DN.

Transforming growth factor (TGF) $\beta$ is a peptide that reacts with different types of cells and is involved in numerous different biological functions, such as promoting cell hypertrophy, accelerating apoptosis and improving the content of the ECM (10). TGF- $\beta$ mediates the synthesis of matrix proteins, such as Col IV and FN, under high glucose conditions and promotes the adhesion between cells and the ECM by increasing the expression of the ECM receptor (11). A previous study have demonstrated that TGF- $\beta$ expression was notably increased in STZ-induced diabetic kidney tissues of rats, which was positively associated with the degree of renal fibrosis (12). Connective tissue growth factor (CTGF) is a downstream target of TGF- $\beta$, and the biological effect of TGF- $\beta$ is partially mediated by CTGF (13). Another previous study demonstrated that CTGF may be associated with the pathogenesis of DN, as patients with DN had increased concentrations of CTCF in peripheral blood and urine. CTCF was also found to be associated with the albuminuria excretion index (14). Furthermore, CTGF is expressed at significantly high levels in the mesangial area of patients and animals with DN compared with normal tissues, and in high glucose-cultured mesangial cells (15). It has also been reported that the concentrations of $\mathrm{FN}$ and collagen are significantly increased in CTGF-treated mesangial cells (16). Taken together, these results suggest that TGF- $\beta$ and CTGF serve important roles in the process of ECM accumulation. However, to the best of our knowledge, whether there is an association between tTG and TGF- $\beta$ or CTGF in DN remains unclear.

Ginkgo biloba leaf extract (GBE) has been widely used to prevent and treat cardiovascular diseases due to its reported ability to induce vasodilation, inhibit the development of atherosclerosis and inflammation, and repress free radicals (17). Analogous effects have also been observed in mesangial cells cultured in high glucose medium, where GBE was demonstrated to decrease the expression levels of TGF- $\beta$ and CTGF, as well as the expression levels of Col IV (18). Our previous study indicated that GBE can be used to prevent and treat renal fibrosis in rats, which may inhibit the Angiotensin (Ang) II-induced upregulation of the mRNA expression levels of TGF- $\beta$ and CTGF (19). However, to the best of our knowledge, the effects of GBE on tTG have not yet been elucidated. Thus, the present study aimed to investigate the effects of GBE on tTG expression in the diabetic kidneys of rats and high glucose-treated mesangial cells to determine whether GBE exerts protective mechanisms.

\section{Materials and methods}

GBE extract. GBE was purchased from JiangSu Xuzhou Huakang Biological Products Co., Ltd. The extract was obtained through ethanol extraction method and the contents of total Ginkgo flavonol glycosides and terpene lactones in
GBE were detected with high-performance liquid chromatography by the aforementioned company. According to the Chinese Pharmacopoeia (2015) (20), the total Ginkgo flavonol glycosides content in GBE is $25.3 \%$ (recommended, $>24.0 \%$ ) and the terpene lactones content in GBE is $6.37 \%$ (recommended, $>6.0 \%$ ), its moisture content is $4.6 \%$ (recommended, $\leq 5.0 \%)$.

Chemical reagents. Streptozotocin (STZ) was purchased from MilliporeSigma. Ginaton (GBE injection) was from Dr Willmar Schwabe GmbH \& Co. KG. Rabbit anti-tTG polyclonal antibody (cat. no. 121495) was from Abcam. Rabbit anti-CTGF polyclonal antibody (cat. no. 323092), anti-TGF- $\beta$ polyclonal antibody (cat. no. 324045), HRP-anti-rabbit IgG and 3,3'-diaminobenzidine (DAB) were from OriGene Technologies, Inc. TRIzol ${ }^{\circledR}$ reagent, molecular weight protein marker, enhanced chemiluminescence (ECL), Lipofectamine ${ }^{\circledR}$ 2000 and SuperScriptII were all from Thermo Fisher Scientific, Inc. Primers were purchased from RuiJie Biological. PVDF membranes were from EMD Millipore. Rabbit anti-FN (cat. no. 0666R) and anti-Col IV (cat. no. 0553R) polyclonal antibodies were from BIOSS. Mouse anti-GAPDH polyclonal antibody (cat. no. 365062) and peroxidase-conjugate secondary antibody (cat. no. sc2004) were from Santa Cruz Biotechnology, Inc. Rat mesangial cells (HBZY-1) were purchased from Wuxi BioHermes Biological Co., Ltd. DMEM was supplied by Gibco; Thermo Fisher Scientific, Inc. TGF- $\beta$ ELISA kit (cat. no. BMS623-3) was from Thermo Fisher Scientific, Inc., FN ELISA kit (cat. no. EK0350) was from Wuhan Boster Biological Technology, Ltd., and Col IV ELISA kit (cat. no. H145) and BCA kit were from Nanjing Jiancheng Bioengineering Institute. CTGF and tTG ELISA kits (cat. nos E90010Ra and E90053Ra) were from YouerSheng Technology Co.,Ltd. Mayer's hematoxylin solution and periodic acid-schiff (PAS) staining were from Beijing Dingguo Changsheng Biotechnology Co., Ltd.

DN animal model protocol. Healthy male Wistar rats (weight, 180-220 g; age, 6 weeks) were provided by the Laboratory Animal Center of Jilin University. All the rats were housed in a pathogen-free facility with free access to a standard dried chow diet and water throughout the period of study. During the present study, the animals were housed in a temperature of $22-26^{\circ} \mathrm{C}$ and a humidity of $50-65 \%$ in a controlled environment with a 12-h light/dark cycle. The padding was changed twice a week and the health status was observed with no mortalities. All the animal experiments were conducted following internationally recognized guidelines proposed by the World Association for the Protection of Animals on animal welfare and the regulations on the administration of laboratory animals in China. All the in vivo experiments were approved by the Animal Experimental Ethical Inspection Committee of Jilin University, School of Pharmaceutical Sciences (ethical permission code 20190014; Changchun, China).

A single intraperitoneal injection of $50 \mathrm{mg} / \mathrm{kg} \mathrm{STZ}$ was used to induce diabetes in the rats. The blood and urine glucose levels of each rat were tested 3 days later. The $\mathrm{DN}$ animal model standard was as follows: Blood glucose level $\geq 16.7 \mathrm{mmol} / \mathrm{l}$ and 24-h urinary albumin excretion $>20-200 \mu \mathrm{g} / \mathrm{min}(21)$. The DN rats were randomly divided into two groups, ten for DN group 
and ten for GBE group. Ten healthy rats for the control group. The GBE group rats were intragastrically administered with $100 \mathrm{mg} / \mathrm{kg}$ GBE once a day (dissolved in $0.5 \%$ carboxymethylcellulose sodium; Beijing Dingguo Changsheng Biotechnology Co., Ltd.), an equal volume of vehicle was given in the control and DN groups for 12 weeks. The rats were subsequently euthanized using pentobarbital sodium $(150 \mathrm{mg} / \mathrm{kg}$ body weight; Beijing Dingguo Changsheng Biotechnology Co., Ltd.) through the intraperitoneal route, followed by cervical dislocation.

Measurement of blood glucose and renal function. Blood and urine of all the rats were collected before the animals were sacrificed at the end of study, and the 24-h urinary albumin excretion and blood glucose were examined using biuret (Beijing Dingguo Changsheng Biotechnology Co., Ltd.) and 7150 Automatic Biochemical Analyzer (Hitachi, Ltd.), respectively.

PAS staining for mesangial matrix expansion. Rats were sacrificed following GBE administration as aforedescribed. Then the whole kidneys were removed completely and fixed in $10 \%$ buffered formalin at room temperature for $24 \mathrm{~h}$, kidney tissues were cut longitudinally in the same position and embedded in paraffin for a light microscopic study (Olympus Corporation). The $5 \mu \mathrm{m}$ kidney tissue sections were all stained with PAS reagent. The paraffin sections were incubated in periodate alcohol solution $(0.088 \mathrm{~mol} / \mathrm{l}$ periodic acid, $0.05 \mathrm{~mol} / \mathrm{l}$ sodium acetate and $4.30 \mathrm{~mol} / \mathrm{l}$ ethyl alcohol) at $17-20^{\circ} \mathrm{C}$ for $10 \mathrm{~min}$. Afterwards, they were washed with $70 \%$ ethanol and transferred into reductant $(0.125 \mathrm{~mol} / \mathrm{l}$ sodium thiosulfate, $10.187 \mathrm{~mol} / 1$ ethyl alcohol, $0.02 \mathrm{~mol} / 1$ $\mathrm{HCl}$ and $0.12 \mathrm{~mol} / \mathrm{l} \mathrm{KI}$ ) at $17-20^{\circ} \mathrm{C}$ for a 10 -min incubation. Subsequently, the sections were washed with $70 \%$ alcohol again and soaked in the PAS solution for 1-1.5 $\mathrm{h}$ at room temperature. The sections were rinsed with running water for $10 \mathrm{~min}$. The nuclei of cells were stained with Mayer's hematoxylin for 3-5 min at room temperature followed by $1 \%$ hydrochloric acid alcohol (1\% concentrated hydrochloric acid and $99 \%$ ethyl alcohol) wash. Finally, the sections were washed with running water for $3 \mathrm{~min}$, and then dehydrated to reinforce the diaphaneity and sealing. Glycogen and mucin in the glomerulus were stained purple by PAS, whereas the nuclei were stained blue by Mayer's hematoxylin. PAS-positive staining areas were analyzed using Image-Pro Plus 6.0 (Media Cybernetics, Inc.) analysis software, and total glomerular tuft areas were analyzed using ImageJ software (version 1.51d; National Institutes of Health). The glomerulosclerosis area (\%) was calculated using the following formula: (PAS-positive staining area/total glomerular tuft area) $\mathrm{x} 100 \%$.

Immunohistochemical analysis of $t T G$ expression. The kidney paraffin sections, prepared as described in the previous section, were dewaxed at $60^{\circ} \mathrm{C}$ for $30 \mathrm{~min}$, and washed with boiled $0.01 \mathrm{~mol} / \mathrm{l} \mathrm{PBS}\left(\mathrm{pH} 7.4,0.0203 \mathrm{~mol} / 1 \mathrm{Na}_{2} \mathrm{HPO}_{4}, 0.00167 \mathrm{~mol} / \mathrm{l}\right.$ $\mathrm{NaH}_{2} \mathrm{PO}_{4}, 0.1367 \mathrm{~mol} / 1 \mathrm{NaCl}$ ) three times (3 min each), blocked in $5 \%$ bovine serum albumin (Beijing Dingguo Changsheng Biotechnology Co., Ltd.) at room temperature for $1 \mathrm{~h}$. Afterwards, the samples were incubated with rabbit anti-tTG antibody for $24 \mathrm{~h}$ at $4^{\circ} \mathrm{C}$ (1:300 dilution), the bound antibodies were subsequently detected with HRP-anti-rabbit IgG for $20 \mathrm{~min}$ at room temperature (1:1,000 dilution) and $\mathrm{DAB}$, followed by counterstaining with Mayer's hematoxylin for $2 \mathrm{~min}$ at room temperature, and negative controls were incubated with PBS. Finally, images were captured under a light microscope (Nikon TE-2000U; Nikon Corporation), and analyzed using Image-Pro Plus 6.0 (Media Cybernetics, Inc.) analysis software.

Culture of HBZY-1 cells. HBZY-1 cells were cultured in low glucose $(5.5 \mathrm{mM})$ DMEM containing $10 \%$ fetal bovine serum (Gibco; Thermo Fisher Scientific, Inc.), 10\% newborn calf serum (Gibco; Thermo Fisher Scientific, Inc.), $100 \mathrm{U} / \mathrm{ml}$ penicillin and $100 \mathrm{mg} / \mathrm{ml}$ streptomycin at $37^{\circ} \mathrm{C}$ with $5 \% \mathrm{CO}_{2}$ and $95 \%$ air. Confluent cells were used for experiments between passages 3 and 7. HBZY-1 cells at $85-90 \%$ confluence were seeded into six-well plates $\left(1 \times 10^{6}\right.$ cells/well $)$ and incubated with high glucose $(30 \mathrm{mM})$ DMEM without serum and different concentrations $(0,3.125,6.25,12.5,25$ and $50 \mu \mathrm{g} / \mathrm{ml})$ of Ginaton at $37^{\circ} \mathrm{C}$ for $24 \mathrm{~h}$. Control group cells were cultured with low glucose $(5.5 \mathrm{mM}) \mathrm{DMEM}$ without serum at $37^{\circ} \mathrm{C}$ for $24 \mathrm{~h}$.

Semi-quantitative reverse transcription- $P C R(R T-P C R)$. Total mRNA was extracted with TRIzol following the manufacturer's protocol. RT-PCR reactions were prepared according to the manufacturer's instructions of SuperScriptII reverse transcriptase $(10,000$ units total, at $200 \mathrm{U} / \mu \mathrm{l} ; 5 \mathrm{X}$ first-strand buffer, $250 \mathrm{~mol} / \mathrm{l}$ Tris-HCl, $375 \mathrm{~mol} / \mathrm{l} \mathrm{KCl}, 15 \mathrm{~mol} / 1 \mathrm{MgCl}_{2}$ ); $100 \mathrm{~mol} / \mathrm{l} \mathrm{DTT})$, using $1 \mu \mathrm{g}$ of total mRNA as the template. The upstream and downstream primers were designed for rat tTG mRNA, and GAPDH mRNA was used for sample normalization. The sequences of the primers used were as follows: tTG forward, 5'-GGCAATGACTTTGACGTGTTT G-3' and reverse, 5'-ATACAGGGAATCAGAAAGTGGGTT C-3'; and GAPDH forward, 5'-ACCACAGTCCATGCCATC AC-3' and reverse, 5'-TCCACCACCCTGTTGCTGTA-3'. The molecular sizes of the amplification products were 396 and $452 \mathrm{bp}$, respectively. The following thermocycling conditions were used for semi-quantitative PCR with DNA polymerase (Thermo Fisher Scientific, Inc.): Initial denaturation at $94^{\circ} \mathrm{C}$ for $5 \mathrm{~min}$; 30 cycles of $94^{\circ} \mathrm{C}$ for $30 \mathrm{sec}, 55^{\circ} \mathrm{C}$ for $30 \mathrm{sec}$ and $72^{\circ} \mathrm{C}$ for $30 \mathrm{sec}$; and a final extension at $72^{\circ} \mathrm{C}$ for $10 \mathrm{~min}$. PCR products $(5 \mu \mathrm{l})$ were used for gel electrophoresis (1\% agarose gel) and target bands visualized by ethidium bromide, the results were utilized to quantify the intensity of nucleic acid bands with ImageJ 1.25 software and calculate the ratio of tTG/GAPDH.

Western blotting. Fresh frozen renal cortical tissues $(100 \mu \mathrm{g})$ were homogenized in $100 \mu \mathrm{l}$ lysis buffer $[0.01 \mathrm{~mol} / \mathrm{l}$ Tris-HCl (pH 7.5), $0.1 \mathrm{~mol} / 1 \mathrm{NaCl}, 0.001 \mathrm{~mol} / \mathrm{lEDTA}, 100 \mu \mathrm{g} / \mathrm{ml}$ PMSF, $1 \mu \mathrm{g} / \mathrm{ml}$ Aprotinin] for $30 \mathrm{~min}$ and thereafter centrifuged at $12,000 \mathrm{x} \mathrm{g}$ for $15 \mathrm{~min}$ at $4^{\circ} \mathrm{C}$. The BCA method was used to quantify the level of protein in each sample to ensure equal protein loading. Proteins were heated with $2 \mathrm{X}$ SDS-PAGE sample buffer [100 mol/1 Tris-HCl (pH 6.8), 200 mol/l DTT, $4 \%$ SDS, $0.2 \%$ bromophenol blue, $20 \%$ glycerin] for $5 \mathrm{~min}$ and separated by SDS-PAGE according to their molecular weight. Briefly, $50 \mu 1$ proteins, along with a molecular 
weight protein marker, were subjected to SDS-PAGE (12\% acrylamide gel) and electroblotted onto PVDF membranes. The membranes were blocked with $5 \%$ non-fat milk in TBS containing $0.1 \%$ Tween-20 for $1 \mathrm{~h}$ at room temperature and then probed at $4^{\circ} \mathrm{C}$ with anti-tTG (1:300 dilution) or anti-GAPDH antibody (1:500 dilution) overnight. After incubation with peroxidase-conjugated secondary antibody (1:5,000 dilution; Santa Cruz Biotechnology, Inc.) for $1 \mathrm{~h}$ at room temperature, membranes were developed using ECL. In addition, rat mesangial cells (HBZY-1) were cultured in vitro for further study, confluent HBZY-1 cells were harvested from 6-well plates, lysed on ice with $100 \mu 1$ lysis buffer (Beijing Dingguo Changsheng Biotechnology Co., Ltd.) per well and centrifuged at $12,000 \mathrm{x} \mathrm{g}$ for $15 \mathrm{~min}$ at $4^{\circ} \mathrm{C}$. The supernatant was collected and western blotting was performed as described above. All the band intensities were analyzed using ImageJ 1.25 software.

MTT assay. HBZY-1 cells in the logarithmic growth phase were dissociated by trypsinization at $37^{\circ} \mathrm{C}$ for $2 \mathrm{~min}$ and seeded into 96 -well plates at a density of $2 \times 10^{4}$ cells/ml and $200 \mu \mathrm{l}$ cell suspension/well overnight. Cells were treated with different concentrations of GBE injection, as described previously, under high glucose $(30 \mathrm{mM})$ DMEM at $37^{\circ} \mathrm{C}$ for $72 \mathrm{~h}$ in order to estimate whether this agent induced cell injury. Subsequently, $20 \mu 1$ MTT ( $5 \mathrm{mg} / \mathrm{ml}$ in PBS) solution was added into each well and the samples were incubated at $37^{\circ} \mathrm{C}$ for $4 \mathrm{~h}$. A total of $150 \mu 1$ dimethylsulfoxide was added to each well and the plates were placed on a shaker at room temperature for $10 \mathrm{~min}$. The absorbance at $570 \mathrm{~nm}$ was measured with a microplate reader (SpectraMax Plus384; Molecular Devices, LLC). The percentage of surviving cells was calculated as a fraction of the negative control group cells which were treated with an equal volume of low glucose $(5.5 \mathrm{mM})$ DMEM.

ELISA for testing the contents of FN, Col IV, tTG, TGF- $\beta$ and $C T G F$. The cells were treated as described in previous sections, then culture supernatant of each sample was collected and diluted with a coating buffer ( $\mathrm{pH} 9.6,0.06 \mathrm{~mol} / \mathrm{l}$ carbonate) at a dilution of 1:9. A total of $100 \mu \mathrm{l}$ diluent was added to each well in the ELISA plate at $4^{\circ} \mathrm{C}$ overnight and the coating buffer without supernatant fluid was used as the control. The coating buffer was removed and samples washed three times with PBS with 5\% Tween-20 (3 min each). The wells were blocked with PBS containing 2\% fetal calf serum (Gibco; Thermo Fisher Scientific, Inc.) for $1.5 \mathrm{~h}$ at $37^{\circ} \mathrm{C}$. The plate was subsequently washed again and incubated with antibodies against tTG, TGF- $\beta$, CTGF, FN and Col IV (1:1,000 dilution) for $1.5 \mathrm{~h}$ at $37^{\circ} \mathrm{C}$. After incubation with a HRP-conjugated secondary antibody $\left(1: 2,000\right.$ dilution) for $1 \mathrm{~h}$ at $37^{\circ} \mathrm{C}$ the supernatant fluid was disposed of and O-phenylenediamine was added and incubated in the dark at room temperature for $5 \mathrm{~min} . \mathrm{H}_{2} \mathrm{SO}_{4}$ was added to stop the reaction and the absorbance value was detected at a wavelength of $490 \mathrm{~nm}$ with a DG5033A Automatic Microplate ELISA Analyzer (Nanjing Huadong Electronics Group Medical Equipment Co., Ltd.).

Transfection with small interfering RNA (siRNA) against $T G F-\beta$ and $C T G F$. HBZY-1 were cultured in 6-well plates to $85-90 \%$ confluence, at which point they were transfected with four separate gene phosphorylated double-stranded siRNA oligonucleotides targeting TGF- $\beta$ (5'-GCAACAAUUCCU GGCGUUA-3', 5'-GCAACAACGCAAUCUAUGA-3', 5'-GGA CUACGCCAAAGAA-3' and 5'-GAACCAAGGAGACGG AAUA-3') or CTGF (5'-GAAGACGCGUUUGGCCCUG-3', 5'-GACAAUACCUUCUGCAGGC-3', 5'-GUGAAGACCUAC CGGGCUA-3' and 5'-CCAAAGCAGUUGCAAAUAC-3') as well as non-specific pooled duplex negative control siRNA (5'-AUGAACGUGAAUUGCUCAAUU-3' and 5'-UUGAGC AAUUCACGUUCAUUU-3') using Lipofectamine ${ }^{\circledR} 2000$, according to the manufacturer's protocol. HBZY-1 at density of $1 \times 10^{6}$ cells/well were plated for at least $24 \mathrm{~h}$ before transfection, and transfected with $5 \mu 1$ siRNA at $37^{\circ} \mathrm{C}$ for $6 \mathrm{~h}$. A total of $6 \mathrm{~h}$ after transfection, the HBZY-1 were exposed to $12.5 \mu \mathrm{g} / \mathrm{ml}$ of GBE for $72 \mathrm{~h}$, and cultured with high glucose $(30 \mathrm{mM})$ DMEM, the control siRNA group were transfected with 5 at $37^{\circ} \mathrm{C}$ for $6 \mathrm{~h}$ and exposed only to high glucose DMEM. Finally, tTG protein expression levels were detected by western blotting, as described above.

Statistical analysis. Statistical analysis was performed using the SPSS 22.0 statistical package (IBM Corp.). The results are presented as the mean $\pm \mathrm{SD}$, and three repeats were performed for each experiment. Differences among all groups were evaluated using one-way analysis of variance with Tukey's post hoc test, correlation analysis were evaluated using Pearson's correlation analysis. $\mathrm{P}<0.05$ was considered to indicate a statistically significant difference.

\section{Results}

GBE decreases blood glucose levels and relieves renal injury in a rat model of $D N$. In the present study, the rat models of DN had blood glucose levels of $\geq 13.8 \mathrm{mmol} / \mathrm{l}$ and a 24 -h urinary albumin excretion of $>20-200 \mu \mathrm{g} / \mathrm{min}(28.8-288 \mathrm{mg} / 24 \mathrm{~h})$, which were significantly higher compared with those in the control group. In addition, the kidney weights of rats with DN were significantly elevated compared with those in the control group (all $\mathrm{P}<0.01$; Fig. 1A-C), and exhibited an increase in the glomerulosclerosis area $(\mathrm{P}<0.01$; Fig. 1D). These results indicated that the STZ-induced rat model of DN had been successfully established. Decreased 24-h urinary albumin excretion levels and lower kidney weights were observed in the GBE group compared with those in the DN group $(\mathrm{P}<0.05)$, and the glomerulosclerosis area was significantly decreased $(\mathrm{P}<0.01)$, suggesting that GBE may not significantly reduce glucose levels, while significantly decrease the renal injury of DN rats.

GBE inhibits $t T G$ expression in rat models of DN. In the present study, histological examination was performed to detect tTG expression levels in kidney tissues, and western blot and PCR analyses were further performed to detect tTG protein and mRNA expression levels, respectively. Immunohistochemistry analysis demonstrated that tTG expression was significantly upregulated in the kidney glomeruli and tubules of rat models of DN compared with that in the control group $(\mathrm{P}<0.01 ;$ Fig. $2 \mathrm{~A})$. Furthermore, $\mathrm{tTG}$ protein $(\mathrm{P}<0.01$; Fig. $2 \mathrm{~B})$ and mRNA levels $(\mathrm{P}<0.01$; Fig. $2 \mathrm{C})$ were significantly higher in $\mathrm{DN}$ rats compared with those in the 
A

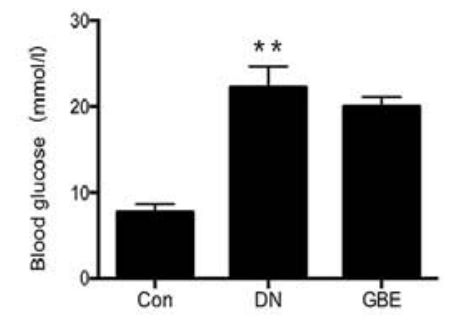

B

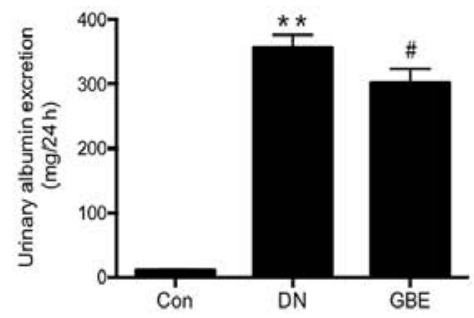

C

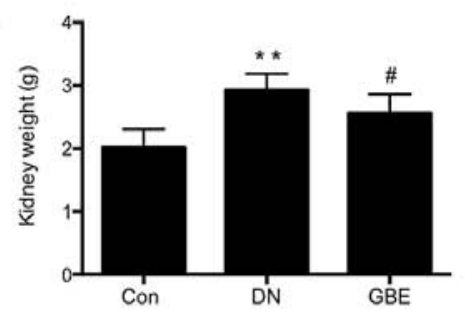

D

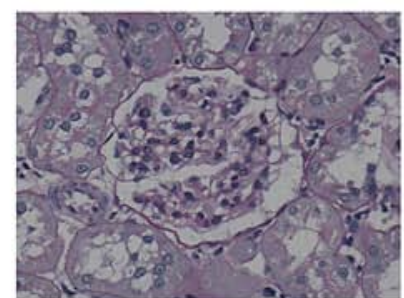

Con

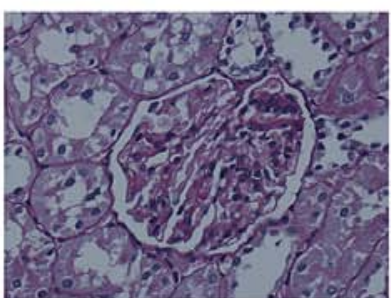

$\mathrm{DN}$

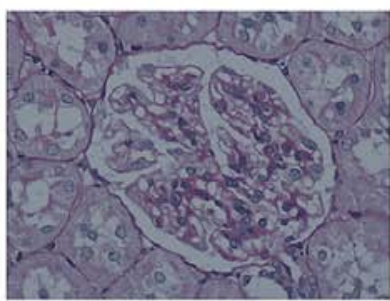

GBE

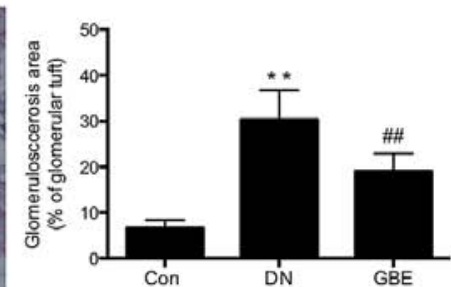

Con

Figure 1. Effect of GBE on blood glucose and renal dysfunctions of rats with DN. (A) Blood glucose levels. (B) Urinary albumin excretion. (C) Kidney weights of rats. (D) Glomerulosclerosis area (magnification, $\mathrm{x} 400$; scale bar, $100 \mu \mathrm{m})$. Data are presented as the mean $\pm \mathrm{SD}$ ( $\mathrm{n}=10$ rats/group). ${ }^{* *} \mathrm{P}<0.01 \mathrm{vs}$. Con group; ${ }^{\#} \mathrm{P}<0.05$ and ${ }^{\# \#} \mathrm{P}<0.01$ vs. DN group. Con, control; DN, diabetic nephropathy; GBE, Ginkgo biloba leaf extract.

A

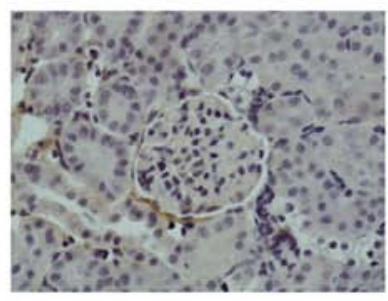

Con

B

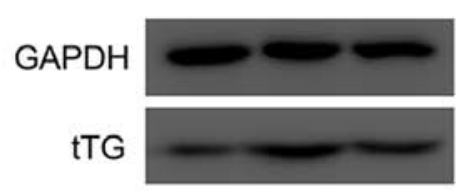

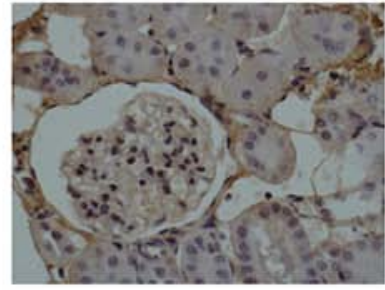

$\mathrm{DN}$

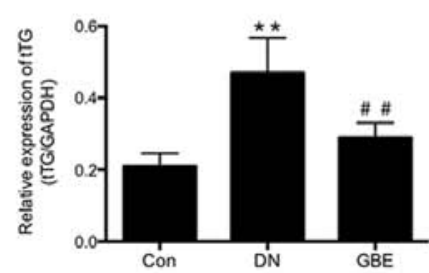

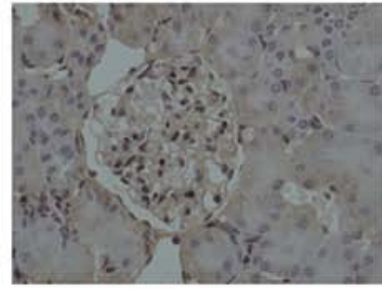

GBE

C

GAPDH

tTG
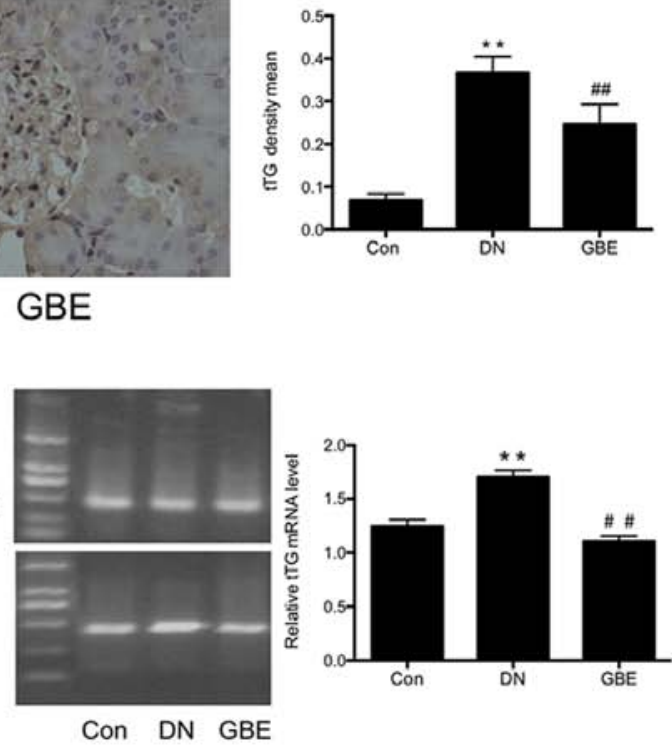

Figure 2. GBE suppresses the expression of tTG in diabetic kidney. (A) Representative immunohistochemistry staining of tTG in kidney (magnification, x400; scale bar, $100 \mu \mathrm{m}$ ). (B) Expression of tTG detected by western blotting in kidney tissues, the protein level was semi-quantified by densitometric analysis. (C) mRNA level of tTG in kidney samples. GAPDH was used as the internal standard in each sample, all values are presented as the mean \pm SD. ${ }^{* *}<<0.01$ vs. Con group; ${ }^{\# \prime} \mathrm{P}<0.05$ vs. DN group. Con, control; DN, diabetic nephropathy; GBE, Ginkgo biloba leaf extract; tTG, tissue transglutaminase.

control rats. Notably, following treatment with GBE, tTG protein $(\mathrm{P}<0.01)$ and mRNA $(\mathrm{P}<0.01)$ levels were significantly decreased compared with those in the DN group.

GBE decreases the expression levels of FN, Col IV, tTG, TGF- $\beta$ and CTGF in high glucose-induced HBZY-1 cells. To determine whether GBE exerted protective effects on HBZY-1 cells, cell viability was assessed using an MTT assay. HBZY-1 cells were treated with different concentrations of GBE for $72 \mathrm{~h}$. The results demonstrated that GBE failed to significantly alter the viability of HBZY-1 cells compared with the control group (Fig. 3A).
The results of the present study demonstrated that Col IV and FN protein levels were increased in HBZY-1 cells treated with high glucose $(\mathrm{P}<0.05$; Fig. $3 \mathrm{~B})$. Following treatment with different concentrations of GBE $(3.125,6.25,12.5,25$ and $50 \mu \mathrm{g} / \mathrm{ml})$ the levels of Col IV and FN were decreased $(\mathrm{P}<0.01)$.

The protein expression levels of tTG, TGF- $\beta$ and CTGF were increased in high glucose-treated HBZY-1 cells compared with those in low glucose-treated HBZY-1 cells $(\mathrm{P}<0.01$; Fig. 3C). Furthermore, GBE significantly downregulated the expression levels of tTG, TGF- $\beta$ and CTGF $(\mathrm{P}<0.01)$. Correlation between tTG and TGF- $\beta$ or CTGF was assessed, and the results demonstrated that tTG expression was closely 

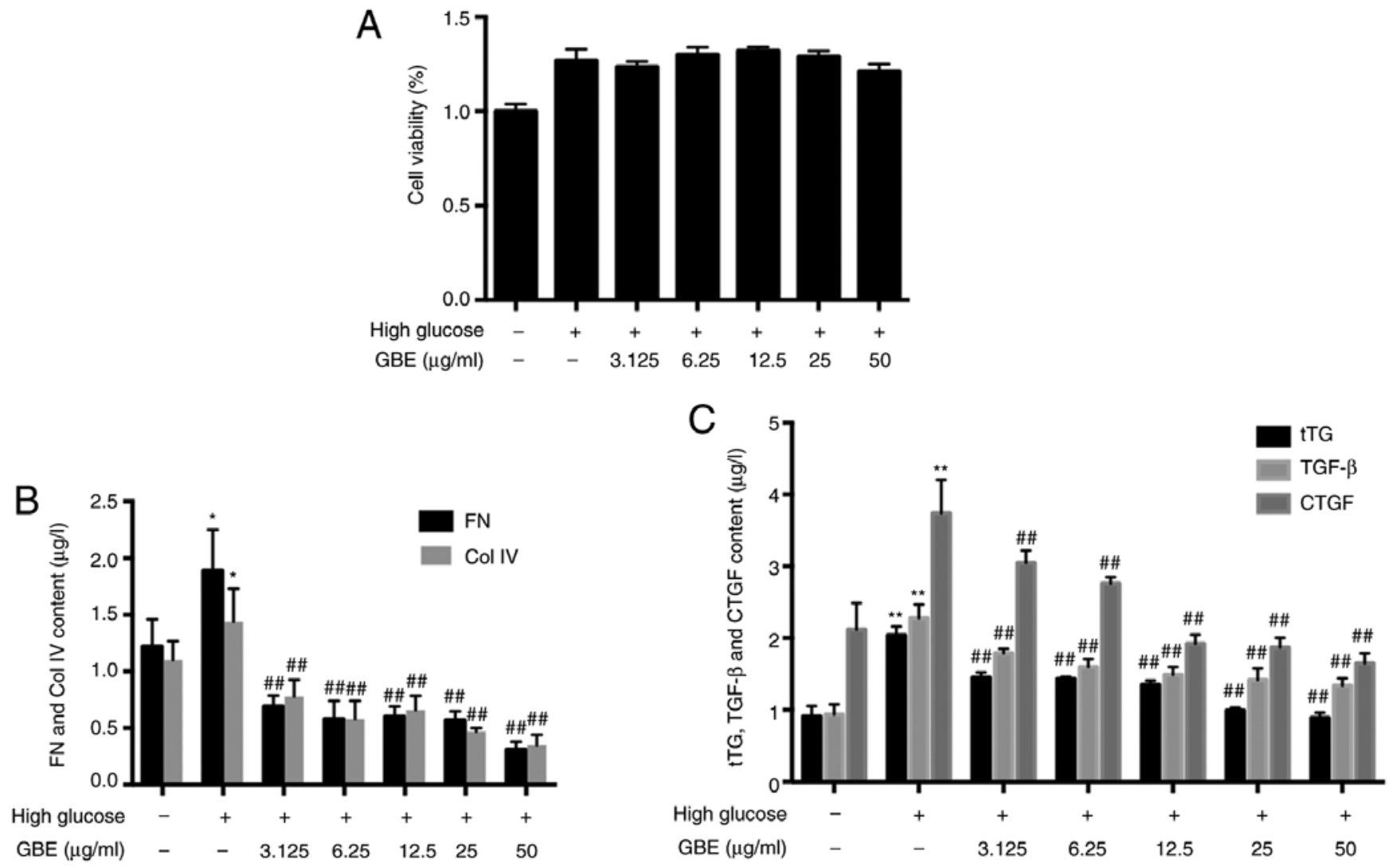

Figure 3. Effects of GBE on secretion of FN, Col IV, tTG, TGF- $\beta$ and CTGF. (A) Effect of GBE on cell viability. (B) Protein levels of FN and Col IV. (C) Protein levels of tTG, TGF- $\beta$ and CTGF. Data are presented as the mean \pm SD. ${ }^{*} \mathrm{P}<0.05$ and ${ }^{* *} \mathrm{P}<0.01$ vs. low glucose control group; ${ }^{\# \#} \mathrm{P}<0.01$ vs. high glucose group. tTG, tissue transglutaminase; FN, fibronectin; Col IV, type IV collagen; TGF- $\beta$, transforming growth factor- $\beta$; CTGF, connective tissue growth factor; GBE, Ginkgo biloba leaf extract.
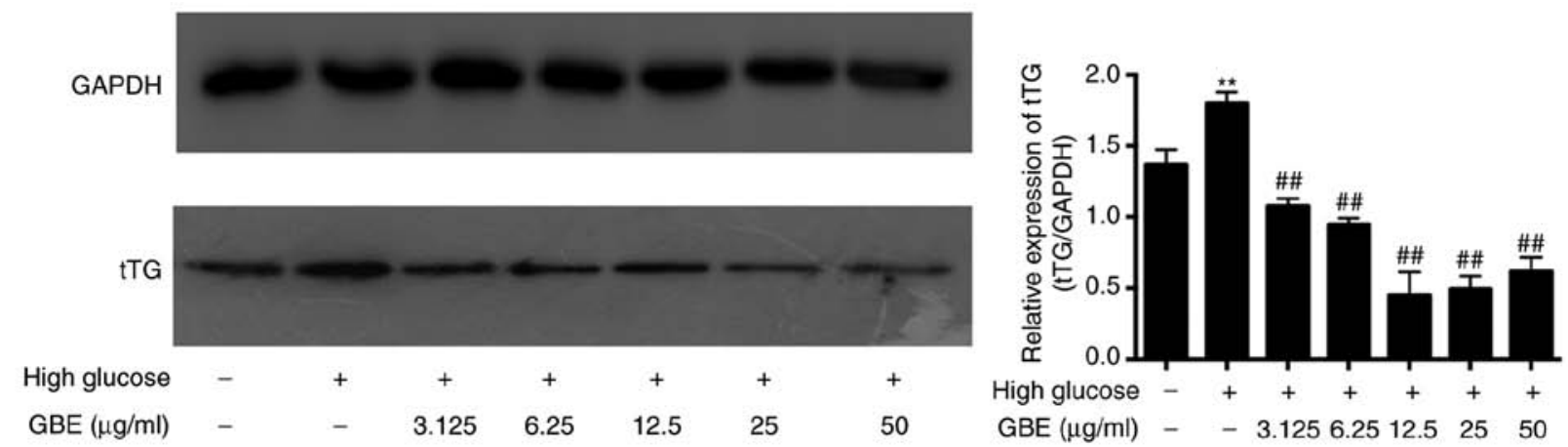

Figure 4. GBE suppresses the expression of tTG in high glucose-treated HBZY-1. GAPDH was used as the internal standard in each sample, the protein level semi-quantification was conducted by densitometric analysis. Data are presented as the mean $\pm \mathrm{SD}$. ${ }^{* *} \mathrm{P}<0.01$ vs. low glucose control group; ${ }^{\# t} \mathrm{P}<0.01 \mathrm{vs}$. high glucose group. tTG, tissue transglutaminase; GBE, Ginkgo biloba leaf extract.

positive associated with both TGF- $\beta$ and CTGF expression $(\mathrm{P}<0.0001$; Table I).

GBE inhibits tTG expression in high glucose-cultured $H B Z Y-1$. Western blot analysis was performed to detect tTG protein expression in high glucose-treated HBZY-1 cells and in cells following treatment with different concentrations of GBE. The results demonstrated that tTG protein expression was significantly increased in high glucose-treated HBZY-1 cells compared with that in low glucose-treated control cells $(\mathrm{P}<0.01$; Fig. 4). Notably, tTG expression decreased following treatment with GBE, in a concentration-dependent manner $(\mathrm{P}<0.01)$. Compared with the high glucose group, $\mathrm{tTG}$ expression levels in the $12.5,25$ and $50 \mu \mathrm{g} / \mathrm{ml}$ GBE-treated groups were reduced by $>50 \%$, and no statistically significant differences were observed between the three groups. Thus, $12.5 \mu \mathrm{g} / \mathrm{ml} \mathrm{GBE}$ was selected for subsequent experimentation. Collectively, these results suggest that GBE may decrease tTG expression in DN.

Role of TGF- $\beta$ and CTGF in the downregulation of $t T G$ expression levels following GBE treatment. Subsequent 

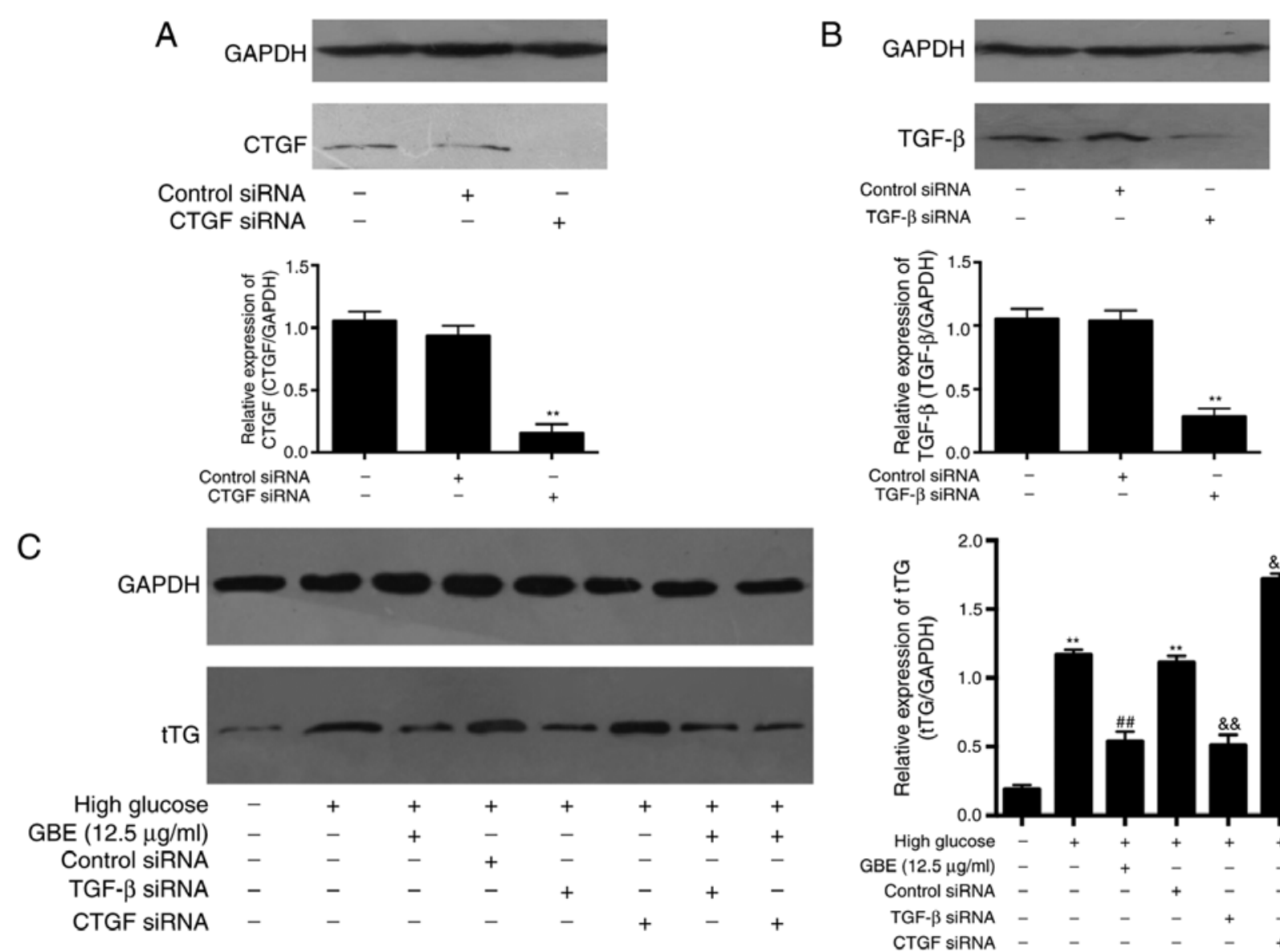

Figure 5. Role of TGF- $\beta$ and CTGF in the GBE-mediated downregulation of tTG protein expression. Effect of (A) CTGF and (B) TGF- $\beta$ siRNA transfection on the protein expression levels of CTGF and TGF- $\beta$, respectively. ${ }^{* *} \mathrm{P}<0.01$ vs. control siRNA. (C) tTG expression was measured by western blotting in cells transfected with CTGF, TGF- $\beta$ or control siRNA and treated with high glucose and $12.5 \mu \mathrm{g} / \mathrm{ml} \mathrm{GBE}$. GAPDH was used as the internal standard in each sample, the protein level was semi-quantified by densitometric analysis. Data are presented as the mean $\pm \mathrm{SD}$. ${ }^{* *} \mathrm{P}<0.01 \mathrm{vs}$. low glucose control group; ${ }^{\# \#} \mathrm{P}<0.01 \mathrm{vs}$. high glucose group; ${ }^{\&} \mathrm{P}<0.01$ vs. control siRNA group; ${ }^{\Delta \Delta} \mathrm{P}<0.01$ vs. CTGF siRNA without GBE group. tTG, tissue transglutaminase; GBE, Ginkgo biloba leaf extract; TGF- $\beta$, transforming growth factor- $\beta$; CTGF, connective tissue growth factor; siRNA, small interfering RNA.

Table I. Correlation analysis between tTG and TGF- $\beta$ and CTGF protein expression levels.

tTG expression

Parameter

Pearson's correlation ( $\mathrm{r}$ values)

$\mathrm{n}$

\begin{tabular}{lll}
\hline TGF- $\beta$ expression & $0.867^{\mathrm{a}}$ & 48 \\
CTGF expression & $0.924^{\mathrm{a}}$ & 48 \\
\hline
\end{tabular}

${ }^{\mathrm{a}} \mathrm{P}<0.0001$. tTG, tissue transglutaminase; TGF- $\beta$, transforming growth factor- $\beta$; CTGF, connective tissue growth factor.

experiments were performed to confirm the involvement of TGF- $\beta$ and CTGF in the protective effects of GBE. Western blot analysis demonstrated that transfection with CTGF or TGF- $\beta$ siRNA significantly inhibited the protein expression levels of CTGF and TGF- $\beta$ compared with those in the respective control siRNA groups (Fig. 5A and B). In addition, transfection with CTGF siRNA failed to significantly decrease tTG protein expression in HBZY-1 cells, while GBE notably inhibited tTG expression in CTGF siRNA-transfected HBZY-1 cells compared with the CTGF siRNA-transfected only group (Fig. 5C), suggesting that increased tTG expression in HBZY-1 cells under high glucose levels may not be regulated by CTGF, and the inhibitory effect of GBE on tTG expression may be independent of CTGF. Transfection with TGF- $\beta$ siRNA significantly decreased tTG protein expression compared with the control siRNA group $(\mathrm{P}<0.01)$, while tTG expression was similar in the GBE, GBE + TGF- $\beta$ siRNA and GBE + CTGF siRNA groups, indicating that the GBE-induced inhibition of tTG expression may be associated with downregulating TGF- $\beta$ expression.

\section{Discussion}

DN is a serious complication of diabetes and is closely associated with the early mortality of affected patients (1). Suppression of high blood glucose levels and high blood pressure is a basic treatment of DN (22). To a certain extent, these methods can effectively delay the onset of kidney disease; however, they fail to inhibit ECM accumulation, resulting in some patients eventually developing end-stage renal disease $(23,24)$. Further studies are required to identify and develop novel treatments to cure DN. Currently, Traditional Chinese Medicine has become an important research focus, with promising new treatments, such as ginkgo (25). ECM accumulation in the glomerular 
mesangium and tubulointerstitium is the main structural feature of $\mathrm{DN}$, and the clinical diagnostic indicators include thickening of the glomerular basement membrane and broadening of the mesangial matrix, as well as albuminuria $(26,27)$. Preliminary studies have demonstrated that GBE affects the protection of kidneys in STZ-induced diabetic rats. For example, it has been reported that blood glucose, 24-h urinary albumin excretion and ECM accumulation notably decreased following treatment with GBE (28). Earlier studies have demonstrated that extract of Ginkgo biloba 761 can inhibit the thickening of the basement membrane and ECM deposition in endotoxaemic rat kidneys, and increase antioxidant enzyme activity to prevent renal tissue damage (29). Lasaite et al (30) treated patients with type 2 diabetes with GBE for 18 months, and revealed that the patients' glycated hemoglobin levels notably decreased, while their quality of life significantly improved. GBE is a Traditional Chinese Medicine that has been previously reported to improve DN (31).

Under continuously high blood glucose levels, tTG expression increases in the tubules and glomeruli (6), which regulates the aggregation of a variety of ECM proteins, including FN, collagen and collagen peptide, thus resulting in the accumulation of the ECM (7). The results of the present study demonstrated that tTG expression increased in the kidneys of diabetic rats, while GBE effectively decreased tTG protein and mRNA levels. TGF- $\beta$ is an important regulatory factor of tTG, which functions as an inducer of several cytokines and fibrosis (32). A number of stimulating factors, such as hyperglycemia, advanced glycation end products and oxidative stress can stimulate the production of TGF- $\beta(33,34)$. In addition, growth factors, such as CTGF, are closely associated with the promotive effect on fibrosis of TGF- $\beta$, and can enhance the biological function of TGF- $\beta$ by combining with the TGF- $\beta$ domain (35). In the present study, the secretion of Col IV and FN was increased in HBZY-1 cells cultured with high glucose, while GBE notably decreased the levels of FN and Col IV, in a concentration-dependent manner. Furthermore, the levels of tTG, TGF- $\beta$ and CTGF were all decreased following treatment with GBE in high glucose-cultured HBZY-1 cells, and tTG expression was positively associated with TGF- $\beta$ and CTGF expression. The siRNA-mediated knockdown of TGF- $\beta$ and CTGF was performed to determine the potential inhibitory mechanism of GBE on tTG. HBZY-1 cells transfected with TGF- $\beta$ siRNA had a markedly impaired ability to upregulate the expression levels of tTG simulated by high glucose exposure, and tTG expression in these cells was similar to that in the GBE-treated HBZY-1 cells transfected with TGF- $\beta$ siRNA. tTG expression was not significantly suppressed following the siRNA-mediated knockdown of CTGF, whereas tTG expression was notably downregulated following treatment with GBE. Taken together, these results suggested that increased tTG expression in HBZY-1 cells under high glucose environments may not be directly mediated by CTGF but by TGF- $\beta$, and GBE may repress tTG expression by inhibiting TGF- $\beta$, which is independent of CTGF. Thus, it may be hypothesized that GBE protects ECM accumulation in DN mainly by inhibiting tTG expression via regulation of TGF- $\beta$.

Cui et al (34) injected human recombinant TGF- $\beta$ into isolated perfused rat kidneys and the results revealed that tTG mRNA expression was upregulated by 8 -fold compared with that in normal rats, resulting in the accumulation of ECM (36). Furthermore, tTG expression is considered to be closely associated with CTGF expression (37). These findings may suggest potential targets for the treatment of DN. DNA methylation is an important regulatory mechanism of CTGF expression, whereby high glucose levels can induce the demethylation process of the CTGF gene promoter and increase CTGF expression in human glomerular mesangial cells or DN model mice, thus altering the expression of its downstream factor (38). In addition, several microRNA (miRNAs/miRs) play an important role in altering TGF- $\beta$ expression levels; for example, upregulated miR-27a expression is closely associated with diabetes, and high glucose-induced upregulation of miR-27a expression activates TGF- $\beta / \mathrm{Smad} 3$ signaling, which contributes to the upregulated changes of CTGF in NRK-52E cells (39). In GBE serum-treated mesangial cells cultured with high glucose medium, Smad2/3 expression decreased, Smad7 expression increased, while Col IV, laminin and TGF- $\beta$ mRNA levels were decreased (40). TGF- $\beta$ receptor 1 has been identified as a target of miR-130b. A previous study demonstrated that miR-130b expression was significantly downregulated in mouse glomerular mesangial cells treated with TGF- $\beta$. Notably, TGF- $\beta$ induced miR-130b suppression via nuclear transcription factor $\mathrm{Y}$ subunit $\gamma$, which subsequently upregulated TGF- $\beta$ receptor 1 to increase the expression of TGF- $\beta$ target fibrotic genes (such as PAI-1), along with upregulating profibrotic genes (Col IV $\alpha 1$ and CTGF) in the progression of DN (26).

The present experiments were the first to observe whether GBE treatment has an effect on DN. After obtaining the present results, screening experiments were performed to identify possible effective chemical elements, and it was initially revealed that the total flavonoids in GBE can notably inhibit ECM accumulation, and a study on its possible mechanism will be published in future. Meanwhile, the total lactone sof GBE, including ginkgolide A, B, C, did not significantly inhibit ECM accumulation, and ECM aggregation represents one of the mechanisms of DN. Whether total lactone level has other renal protective mechanisms requires further experiments to elucidate. In future studies, microarray detection will be performed to identify the potential miRNAs that are involved in the regulation of TGF- $\beta$ by GBE, and to further verify the potential protective mechanism of GBE on DN, which may help to determine novel therapeutic strategies for the prevention and treatment of kidney injury-associated diseases.

In conclusion, the results of the present study demonstrated that GBE decreased tTG expression both in DN rats and rat mesangial cells in vitro under high glucose conditions, and GBE may protect rat mesangial cells by inhibiting tTG via modulating TGF- $\beta$ expression, thus providing a novel strategy for the treatment of DN.

\section{Acknowledgements}

Not applicable.

\section{Funding}

The present study was supported by the Technology Development Planning Projects of Jilin, China (grant 
nos. 20180414026GH and 20190201086JC) and the National Natural Science Foundation of China (grant no. 30800423).

\section{Availability of data and materials}

The datasets used and/or analyzed during the current study are available from the corresponding author on reasonable request.

\section{Authors' contributions}

XY and QS conceived and designed the study. JG, HL, YL, JL and YS performed the experiments. XY and QS wrote the manuscript. $Y Z$ and $X Y$ analyzed the data. $Y Z$ reviewed and edited the manuscript. $\mathrm{YZ}$ and $\mathrm{XY}$ confirm the authenticity of all the raw data. All authors read and approved the final version of the manuscript.

\section{Ethics approval and consent to participate}

All the in vivo experiments were approved by the Animal Experimental Ethical Inspection Committee of Jilin University School of Pharmaceutical Sciences (ethical permission code, 20190014; Changchun, China).

\section{Patient consent for publication}

Not applicable.

\section{Competing interests}

The authors declare that they have no competing interests.

\section{References}

1. Guthrie RA and Guthrie DW: Pathophysiology of diabetes mellitus. Crit Care Nurs Q 27: 113-125, 2004.

2. Islam MA, Amin MN, Siddiqui SA, Hossain MP, Sultana F and Kabir MR: Trans fatty acids and lipid profile: A serious risk factor to cardiovascular disease, cancer and diabetes. Diabetes Metab Syndr 13: 1643-1647, 2019.

3. Schmidt AM: Highlighting diabetes mellitus: The epidemic continues. Arterioscler Thromb Vasc Biol 38: e1-e8, 2018.

4. Tung CW, Hsu YC, Shih YH, Chang PJ and Lin CL: Glomerular mesangial cell and podocyte injuries in diabetic nephropathy. Nephrology (Carlton) 23 (Suppl 4): S32-S37, 2018.

5. Schelling JR: Tissue transglutaminase inhibition as treatment for diabetic glomerular scarring: It's good to be glueless. Kidney Int 76: 363-365, 2009

6. Skill NJ, Johnson TS, Coutts IG, Saint RE, Fisher M, Huang L, El Nahas AM, Collighan RJ and Griffin M: Inhibition of transglutaminase activity reduces extracellular matrix accumulation induced by high glucose levels in proximal tubular epithelial cells. J Biol Chem 279: 47754-47762, 2004.

7. Fleckenstein B, Qiao SW, Larsen MR, Jung G, Roepstorff P and Sollid LM: Molecular characterization of covalent complexes between tissue transglutaminase and gliadin peptides. J Biol Chem 279: 17607-17616, 2004.

8. El Nahas AM, Abo-Zenah H, Skill NJ, Bex S, Wild G, Griffin M and Johnson TS: Elevated epsilon-(gamma-glutamyl)lysine in human diabetic nephropathy results from increased expression and cellular release of tissue transglutaminase. Nephron Clin Pract 97: c108-c117, 2004.

9. Skill NJ, Griffin M, El Nahas AM, Sanai T, Haylor JL, Fisher M, Jamie MF, Mould NN and Johnson TS: Increases in renal epsilon-(gamma-glutamyl)-lysine crosslinks result from compartment-specific changes in tissue transglutaminase in early experimental diabetic nephropathy: Pathologic implications. Lab Invest 81: 705-716, 2001.
10. Loeffler I and Wolf G: Transforming growth factor- $\beta$ and the progression of renal disease. Nephrol Dial Transplant 29 (Suppl 1): i37-i45, 2014.

11. Border WA and Noble NA: Evidence that TGF-beta should be a therapeutic target in diabetic nephropathy. Kidney Int 54: 1390-1391, 1998.

12. Sutariya B, Jhonsa D and Saraf MN: TGF- $\beta$ : The connecting link between nephropathy and fibrosis. Immunopharmacol Immunotoxicol 38: 39-49, 2016.

13. Lee HS: Paracrine role for TGF- $\beta$-induced CTGF and VEGF in mesangial matrix expansion in progressive glomerular disease. Histol Histopathol 27: 1131-1141, 2012.

14. Roestenberg P, van Nieuwenhoven FA, Wieten L, Boer P, Diekman T, Tiller AM, Wiersinga WM, Oliver N, Usinger W, Weitz S, et al: Connective tissue growth factor is increased in plasma of type 1 diabetic patients with nephropathy. Diabetes Care 27: 1164-1170, 2004

15. Wahab NA, Yevdokimova N, Weston BS, Roberts T, Li XJ, Brinkman $\mathrm{H}$ and Mason RM: Role of connective tissue growth factor in the pathogenesis of diabetic nephropathy. Biochem J 359: 77-87, 2001

16. Rosenbloom J, Ren S and Macarak E: New frontiers in fibrotic disease therapies: The focus of the Joan and Joel rosenbloom center for fibrotic diseases at thomas jefferson university. Matrix Biol 51: 14-25, 2016.

17. Lu Q, Yin XX, Wang JY, Gao YY and Pan YM: Effects of Ginkgo biloba on prevention of development of experimental diabetic nephropathy in rats. Acta Pharmacol Sin 28: 818-828, 2007.

18. Ji L, Yin XX, Wu ZM, Wang JY, Lu Q and Gao YY: Ginkgo biloba extract prevents glucose-induced accumulation of ECM in rat mesangial cells. Phytother Res 23: 477-485, 2009.

19. Wang D, Li X, Yu X, Shi Y and Yin L: Expression of tissue transglutaminase on renal interstitial fibrosis rats and intervention of GBE. Zhongguo Zhong Yao Za Zhi 34: 1133-1136, 2009 (In Chinese).

20. Chinese Pharmacopoeia Commission. Pharmacopoeia of the People's Republic of China. Vol. 1. Beijing. China Medical Science and Technology Press, 2015.

21. Yang M, Kan L, Wu L, Zhu Y and Wang Q: Effect of baicalin on renal function in patients with diabetic nephropathy and its therapeutic mechanism. Exp Ther Med 17: 2071-2076, 2019.

22. Afghahi H, Svensson MK, Pirouzifard M, Eliasson B and Svensson AM: Blood pressure level and risk of major cardiovascular events and all-cause of mortality in patients with type 2 diabetes and renal impairment: An observational study from the swedish national diabetes register. Diabetologia 58: 1203-1211, 2015.

23. Rogers NM, Teubner DJ and Coates PT: Calcific uremic arteriolopathy: Advances in pathogenesis and treatment. Semin Dial 20: 150-157, 2007.

24. Eberhardt W, Engels C, Müller R and Pfeilschifter J: Mechanisms of dexamethasone-mediated inhibition of cAMP-induced tPA expression in rat mesangial cells. Kidney Int 62: 809-821, 2002.

25. Fang J, Wang Z, Wang $P$ and Wang M: Extraction, structure and bioactivities of the polysaccharides from Ginkgo biloba: A review. Int J Biol Macromol 162: 1897-1905, 2020.

26. Castro NE, Kato M, Park JT and Natarajan R: Transforming growth factor $\beta 1$ (TGF- $\beta 1$ ) enhances expression of profibrotic genes through a novel signaling cascade and microRNAs in renal mesangial cells. J Biol Chem 289: 29001-29013, 2014.

27. Solini A, Manca ML, Penno G, Pugliese G, Cobb JE and Ferrannini E: Prediction of declining renal function and albuminuria in patients with type 2 diabetes by metabolomics. J Clin Endocrinol Metab 101: 696-704, 2016.

28. Tian J, Popal MS, Liu Y, Gao R, Lyu S, Chen K and Liu Y: Ginkgo biloba leaf extract attenuates atherosclerosis in streptozotocin-induced diabetic ApoE ${ }^{-/}$mice by inhibiting endoplasmic reticulum stress via restoration of autophagy through the mTOR signaling pathway. Oxid Med Cell Longev 2019: 8134678, 2019.

29. Coskun O, Armutcu F, Kanter M and Kuzey GM: Protection of endotoxin-induced oxidative renal tissue damage of rats by vitamin E or/and EGb 761 treatment. J Appl Toxicol 25: 8-12, 2005.

30. Lasaite L, Spadiene A, Savickiene N, Skesters A and Silova A: The effect of Ginkgo biloba and Camellia sinensis extracts on psychological state and glycemic control in patients with type 2 diabetes mellitus. Nat Prod Commun 9: 1345-1350, 2014. 
31. Cui JF, Yang W, Xie YM, Sun Y, Zhuang Y and Wang YY: Real-world analysis of concurrent diseases and medicine use among patients with insomnia. Zhongguo Zhong Yao Za Zhi 39: 3519-3526, 2014 (In Chinese).

32. Pohlers D, Brenmoehl J, Löffler I, Müller CK, Leipner C, Schultze-Mosgau S, Stallmach A, Kinne RW and Wolf G: TGF-beta and fibrosis in different organs-molecular pathway imprints. Biochim Biophys Acta 1792: 746-756, 2009.

33. Serban AI, Stanca L, Geicu OI, Munteanu MC and Dinischiotu A RAGE and TGF- $\beta 1$ cross-talk regulate extracellular matrix turnover and cytokine synthesis in AGEs exposed fibroblast cells. PLoS One 11: e0152376, 2016.

34. Cui Y, Robertson J, Maharaj S, Waldhauser L, Niu J, Wang J, Farkas L, Kolb M and Gauldie J: Oxidative stress contributes to the induction and persistence of TGF- $\beta 1$ induced pulmonary fibrosis. Int J Biochem Cell Biol 43: 1122-1133, 2011.

35. Yin $\mathrm{Q}$ and Liu $\mathrm{H}$ : Connective tissue growth factor and renal fibrosis. Adv Exp Med Biol 1165: 365-380, 2019.

36. Douthwaite JA, Johnson TS, Haylor JL, Watson P and El Nahas AM: Effects of transforming growth factor-beta1 on renal extracellular matrix components and their regulating proteins. J Am Soc Nephrol 10: 2109-2119, 1999.
37. Akimov SS and Belkin AM: Cell-surface transglutaminase promotes fibronectin assembly via interaction with the gelatin-binding domain of fibronectin: A role in TGFbeta-dependent matrix deposition. J Cell Sci 114: 2989-3000, 2001.

38. Zhang H, Cai X, Yi B, Huang J, Wang J and Sun J: Correlation of CTGF gene promoter methylation with CTGF expression in type 2 diabetes mellitus with or without nephropathy. Mol Med Rep 9: 2138-2144, 2014.

39. Hou X, Tian J, Geng J, Li X, Tang X, Zhang J and Bai X: MicroRNA-27a promotes renal tubulointerstitial fibrosis via suppressing PPAR $\gamma$ pathway in diabetic nephropathy. Oncotarget 7: 47760-47776, 2016.

40. Tang D, Zhang Z, Gao Y, Wei Y and Han L: Protective effects of serum containing Ginkgo biloba extract on glomerulosclerosis in rat mesangial cells. J Ethnopharmacol 124: 26-33, 2009.

(i) (3) This work is licensed under a Creative Commons (c) At No Atribution-NonCommercial-NoDerivatives 4.0 International (CC BY-NC-ND 4.0) License. 